\title{
KATA TANYA DALAM KONSTRUKSI \\ KALIMAT INTEROGATIF BAHASA KULAWI \\ (KAJIAN BERDASARKAN BENTUK DAN FUNGSI)
}

\author{
(INTEROGATIVE WORDS IN THE CONSTRUCTION \\ OF INTEROGATIVE SENTENCES IN KULAWI LANGUAGE A \\ BASED-ON-FORM AND FUNCTION STUDY)
}

\author{
M. Asri B. \\ Balai Bahasa Provinsi Sulawesi Tengah \\ Jalan Untad I, Bumi Roviga, Tondo, Palu 94118 \\ Telepon (0451) 4705498; 421874 \\ Pos-el: asritoroviga@ymail.com
}

\begin{abstract}
The purpose of this research was to describe the forms of interrogative sentences and also the function of interrogative words in constructing interrogative sentence of Kulawi Language $(K L)$. Quantitative method is the method of this research. The result of this research indicated that there were three forms of interrogative sentence in $K L$ and three were seven kinds of interrogative words which have different functions.
\end{abstract}

Key words: Interrogative words, interrogative sentence, Kulawi Language.

\begin{abstract}
Abstrak
Penelitian ini bertujuan untuk mendeskripsikan bentuk-bentuk kalimat interogatif serta fungsi kata tanya dalam konstruksi kalimat interogatif bahasa Kulawi (BK). Metode yang digunakan dalam penelitian ini adalah metode kualitatif. Hasil penelitian ini menunjukkan bahwa terdapat tiga bentuk kalimat interogatif dalam BK dan terdapat tujuh jenis kata tanya yang masing-masing memiliki fungsi yang berbeda.
\end{abstract}

Kata Kunci: kata tanya, kalimat interogatif, bahasa Kulawi

\section{Pendahuluan}

Bahasa Kulawi(BK) merupakan bahasa pergaulan yang dipakai masyarakat Kulawi di Kabupaten Sigi Biromaru, Provinsi Sulawesi Tengah. Di samping sebagai bahasa pergaulan, BK juga memiliki kedudukan dan fungsi yang penting di kawasan nusantara, di antaranya berfungsi sebagai (a) lambang kebang- gaan daerah Sulawesi Tengah dan pendukung perkembangan kebudayaan masyarakat Kulawi, (b) lambang identitas Sulawesi Tengah dan masyarakat Kulawi sebagai salah satu suku bangsa di Indonesia, dan (c) alat perhubungan dalam komunikasi lisan pada keluarga dan masyarakat Kulawi, termasuk antaretnis di Sulawesi Tengah. Selain itu, BK juga 
memiliki karakteristik dan keunikan tersendiri yang cukup menarik untuk diungkapkan, di antaranya adalah stuktur bahasanya yang berbeda dengan bahasa Indonesia dan bahasa-bahasa daerah lainnya di Sulawesi Tengah.

Karakteristik atau keunikan yang dimiliki oleh setiap bahasa terjadi karena memang setiap bahasa di dunia ini memiliki sebuah sistem kata, aturan, kaidah-kaidah, dan pola tertentu dalam pemakaiannya, termasuk juga BK. Di samping memiliki perbedaan, bahasa-bahasa yang ada di belahan dunia ini juga memilki kesamaan. Berkaitan dengan itu, (Chaer, 2003:4) mengatakan bahwa bahasa itu merupakan suatu sistem yang pada umumnya juga memiliki subsistem berupa subsistem leksikon, subsistem gramatika, dan subsistem fonologi. Komponen makna berisi konsep-konsep, ide-ide, pikiranpikiran, atau pendapat-pendapat yang berada dalam otak atau pemikiran manusia. Komponen leksikon dengan satuannya yang disebut leksem merupakan wadah penampung makna secara leksikal, juga bersifat abstrak. Komponen gramatika atau subsistem gramatika terbagi lagi menjadi dua subsistem, yaitu subsistem morfologidan subsistem sintaksis.

Subsistem sintaksis membicarakan penataan dan pengaturan kata ke dalam satuan-satuan yang lebih besar, yang disebut satuan-satuan sintaksis, yakni kata, frase, klausa, kalimat, dan wacana. Berkaitan dengan itu, kata merupakan unsur yang sangat penting dalam bahasa, karena kata itulah yang menjadi perwujudan bahasa. Chaer (2006: 86) mengungkapkan bahwa setiap kata mengandung konsep makna dan mempunyai peran dalam pelaksanaan bahasa. Konsep dan peran apa yang dimiliki bergantung pada jenis dan macam kata-kata itu, serta penggunaannya di dalam kalimat. Dilihat darikonsep makna dan peran yang dimilikinya, kata dibedakan atas beberapa jenis kata, yaitu (1) kata benda, (2) kata ganti, (3) kata kerja, (4) kata sifat, (5) kata sapaan, (6) kata penunjuk, (7) kata bilangan, (8) kata penyangkal, (9) kata depan, (10) kata penghubung, (11) kata keterangan, (12) kata tanya, (13) kata seru, (14) kata sandang, dan (15) kata partikel.

Salah satu jenis kata dan yang akan menjadi konsentrasi dalam makalah ini adalah jenis kata tanya atau interogatifBK yang berjumlah tujuh jenis, yaitu (1) napa 'apa',(2) hema 'siapa', (3) nongkua 'mengapa',(4) bewa 'bagaimana', (5) uma 'mana', (6) boloma 'kapan', dan(7) hangkua 'berapa'. Ketujuh jenis kata tanya ini akan dikaji berdasarkan fungsi yang diemban masing-masing.

\section{Kerangka Teori}

\subsection{Definisi Kata Tanya}

Kata adalah satuan ujaran yang berdiri sendiri yang terdapat di dalam kalimat, dapat dipisahkan, dapat ditukar, dapat dipindahkan, dan mempunyai makna serta digunakan untuk berkomunikasi (Ramlan, 1983: 28). Dalam KBBI (Depdikbud, 1993: 451), kata dapat diartikan sebagai (1) unsur bahasa yang diucapkan atau dituliskan yang merupakan perwujudan kesatuan perasaan dan pikiran yang dapat digunakan dalam berbahasa, (2) ujar, bicara, (3) morfem atau kombinasi morfem.

Jika ditinjau dari jenisnya, kata dalam bahasa Indonesia sangat beragam. Salah satu di antaranya adalah kata tanya. Falah (1988: 80) menjelaskan bahwa kata gantipenanya atau pronomina interogatif adalah kata yang menyatakan tentang keadaan suatu benda, baik orang maupun benda mati yang berfungsi memperoleh penjelasan. Selanjutnya, Chaer (2006: 182) menyatakan bahwa kata tanya adalah katakata yang digunakan sebagai pembantu di dalam kalimat yang menyatakan pertanyaan.

Sejalan dengan Chaer, Kridalaksana (2001: 101) menjelaskan bahwa kata tanya (interrogative word, wh-word, question word) adalah kata yang dipakai sebagai penanda pertanyaan dalam kalimat tanya.

Dari beberapa pendapat mengenai definisi kata tanya dapat disimpulkan bahwa kata tanya adalah satuan ujaran yang digunakan untuk menjelaskan atau memberikan jawaban terhadap kalimat pertanyaan.

\subsection{Pembagian Kata Tanya Berdasarkan Fungsinya}

Falah (1988: 80) menjelaskan bahwa kata ganti penanya apabila ditinjau dari segi bentuk dan fungsinya dapat dibedakan menjadi tiga, yaitu (1) untuk menya- 
takan benda dengan menggunakan kata tanya apa, misalnya: Apakah benda itu milikmu?, (2) untuk menyatakan orang dengan menggunakan kata tanya siapa, misalnya: Siapa penghuni rumah itu?, dan (3) untuk menyatakan pilihan dengan menggunakan kata tanya mana, misalnya: Kau pilih baju yang mana?

Dalam hal pembagian kata tanya berdasarkan fungsinya, Chaer lebih variatif dibandingkan dengan Falah. Chaer (2006: 182) membagi kata tanya ke dalam sepuluh jenis kata, yaitu: apa, siapa, mengapa, kenapa, bagaimana, berapa, mana, kapan, bila, dan bilamana. Kesepuluh jenis kata tanya itu mempunyai fungsi atau kegunaan yang berbeda-beda.

\subsection{Definisi Kalimat Tanya}

Kalimat tanya adalah kalimat yang biasanya digunakan untuk meminta informasi tentang sesuatu dari lawan bicara. Kalimat tanya disebut juga kalimat interogatif(Alwi dkk., 2003: 9). Selanjutnya, Kridalaksana (2001: 93) dan Dola (2010: 85) juga mengemukakan bahwa kalimat tanya adalah kalimat yang mengandung intonasi introgatif dan pada umumnya mengandung makna pertanyaan; dalam ragam tulis biasanya ditandai oleh tanda tanya (?). Ditambahkan pula bahwa dalam bahasa Indonesia ditandai oleh kah, apa, bagaimana, dan sebagainya.

Kalimat pertanyaan adalah kalimat yang mengharapkan tanggapan berupa jawaban berbentuk ujaran (Kusharyanti, 2005: 133). Dari segi fungsinya, Ramlan(1996: 33) juga mengutarakan bahwa kalimat tanya adalah kalimat yang berfungsi untuk menanyakan sesuatu dan memilki pola intonasi yang berbeda dengan kalimat lainnya, seperti kalimat berita atau kalimat deklaratif.

\subsection{Jenis atau Tipe Kalimat Tanya}

Berkaitan dengan jenis dan tipe kalimat tanya atau interogatif, Verhaar (1996: 246) menyatakan bahwa dalam setiap bahasa terdapat dua jenis klausa interogatif, yaitu (1) jenis pertanyaan ya/tidak (pertanyaan y/t) dan (2) pertanyaan apa.

Jenis pertanyaan "ya/tidak" (pertanyaan $y / t$ ) adalah pertanyaan yang jawabannya dapat berupa "ya atau tidak". Misalnya: Apakah Anda sudah makan? Selanjutnya, Jenis pertanyaan "apa" adalah pertanyaan dengan konstituen interogatif seperti apa? Siapa?,mengapa, berapa?, dan lain sebagainya. Pertanyaan "apa" tidak dapat dijawab dengan "ya/tidak" dan menuntut informasi yang lain.

Berdasarkan penjelasan di atas, kalimat interogatif dibedakan menjadi dua jenis, yaitu pertanyaan "ya atau tidak" dan pertanyaan "apa".

\section{Metode Penelitian}

Metode yang digunakan dalam penelitian ini adalah metode kualitatif. Metode kulalitatifadalah salah satu metode pengkajian atau metode penelitian terhadap suatu masalah yang tidak dirancang dengan menggunakan prosedur-prosedur statistik (Subroto, 1992: 6).

Ada tiga tahapan metode yang digunakan dalam penelitian ini yaitu (1) tahap pengumpulan data, (2) tahapan analisis data, dan (3) tahapan penyajian hasil analisi data (Sudaryanto, 1993: 9). Pada tahapan pengumpulan data digunakan metode lapangan, yaitu metode pengumpulan data yang dilakukan untuk mendapatkan data primer dengan cara terjung langsung ke lapangan bertemu dengan informan (penutur). Metode ini dibantu oleh teknik elisitasi, yaitu peneliti langsung bertanya kepada informan dengan cara mempersiapkan sejumlah pertanyaan, baik lisan maupun tulis untuk mendapatkan data yang sesuai dengan sasaran yang diinginkan. Selain metode lapangan, digunakan juga metode pustaka. Metode pustaka digunakan untuk mencari data tulis (sekunder), yaitu melalui penelaahan kepustakaan yang memuat data yang ada kaitannya dengan penelitian yang dilakukan, berupa buku-buku maupun hasil penelitian, baik cetak maupun elektronik (internet). Metode pustaka dibantu dengan teknik pencatatan dan terjemahan.

Selanjutnya, pada tahap analisis data digunakan metode agih, yaitu metode yang alat penentunya merupakan bagian dari bahasa itu sendiri, seperti kata, fungsi sintaksis, klausa, dan sebagainya (Sudaryanto, 1993: 15-16). Pelaksanaan metode agih ini dijabarkan dalam suatu teknik dasar dan teknik lanjutan. Teknik dasar yang dimaksud, yaitu teknik bagi unsur langsung (BUL) yang mengandalkan intuisi peneliti. Teknik bagiunsur langsung merupakan teknik analisis dengan cara membagi satuan lingual datanya menjadi 
beberapa bagian atau unsur yang dipandang sebagai bagian yang langsung membentuk satuan lingual yang dimaksud (Sudaryanto, 1993: 31).

Pada tahap pemaparan hasil analisis data, penyajiannya menggunakan teknik informal. Teknik informal adalah perumusan dengan menggunakan kata-kata biasa (Sudaryanto, 1993: 144-146).

\section{Pembahasan}

\subsection{Bentuk Kalimat Interogatif Bahasa Kulawi}

Menurut bentuknya, kalimat interogatif dalam BK terdiri atas tiga, yaitu (1) kalimat interogatifYaTidak, (2) kalimat interogatif informasi, dan (3) kalimat interogatif retorik. Ketiga bentuk kalimat interogatif ini akan diuraikan berikut.

\section{1) Kalimat Interogatif Ya - Tidak}

Kalimat interogatif ya - tidak adalah kalimat interogatifyang dapat dijawab dengan perkataan ya atau tidak. Di dalam BK, kalimat interogatifjenis ini ditandai dengan pemakaian kata tanya apa atau apakah atau tanpa kata tanya, tetapi dengan penambahan kata tidak, atau dengan inversi.

Contoh:

\section{Wetutuko ba tado?}

'Kau mau ikut atau tidak?'

Ba tado nadua ana edou?

'Apa anak itu tidat sakit?'

Ba naratawo tuwpu?

'Sudah datangkah nenek?'

To tua bangkelo edu

to nasodo ba tado?

'Ibu itu pemarah atau tidak?'

Ba tou edou nopangiu doiwu?

'Apa orang itu mencuriuangmu?'

Ni pobelowa roti odou?

'Apakah kau suka kue itu?'

\section{2) Kalimat Interogatif Informasi}

Kalimat interogatifinformasi adalah kalimat interogatif yang menghendaki jawaban berupa informasi. Di dalam BK, pertanyaan seperti ini dibentuk dengan pemakaian kata tanya apa, siapa, berapa, bagaimana, yang mana, mengapa, kapan, dan sebagainya.

Contoh:

Napa kesiui kotak edou?

'Apa isi kotak itu?'

Hema nu keo ri sounu?

'Siapa yang menangis di rumahmu?'

Bewa kareba tinamu?

'Bagaimana keadaan ibumu?'

To umba kuburuna?

'Yang mana kuburannya?'

Napa kundimu?

'Apa yang kau makan?'

Hema manponoasiku?

'Siapa yang menemani saya?'

Hangkua olina uta ei?

'Berapa harga sayur ini?'

Hemano tana loka ei?

'Siapa yang menanam pisang ini?'

Napa laaiyyala naana itue?

'Apa yang diambil anak itu?'

Bewa kareba ompita i ngata?

'Bagaimana keadaan keluarga kita di kampung?'

Nongkoako nalino?

'Mengapa engkau termenung?'

Bolomako narata?

'Kapan engkau datang?' 


\section{3) Kalimat Interogatif Retorik}

Kalimat interogatif retorik adalah jenis kalimat tanya yang tidak memerlukan jawaban, melainkan menghendaki penegasan dari orang yang tidak diajak bicara. Pertanyaan retorik di dalam BK dinyatakan dengan penambahan kata bukan pada akhir kalimat. Contoh:

Calon ininantua nagaya, tado?

'Calon istrimu cantik, bukan?'

Pana tadopa nauri, tado?

'Kakinya belum sembuh, bukan?'

Bengkele edu naya, tado?

'Gadis itu pemalu, bukan?'

Tomana topo poroko, tado?

'Ayahnya perokok, bukan?'

Tinamu guru, tado?

'Ibumu guru, bukan?'

\subsection{Jenis dan Fungsi Kata Tanya Bahasa Kulawi}

Fungsi kalimat interogatif adalah untuk menanyakan sesuatu. Kalimat interogatif dalam BK ada yang menggunakan kata tanya dan ada yang tidak menggunakan kata tanya. Jenis kata tanya yang digunakan dalam BK, antara lain, adalah (1) napa 'apa', (2) hema 'siapa', (3) nongkua 'mengapa', (4) bewa 'bagaimana', (5) uma 'mana', (6) boloma kapan', dan (7) hangkua 'berapa'. Jenis-jenis kata tanya tersebut mempunyai fungsi masing-masing yang akan diuraikan berikut.

\section{1) Kata Tanya Napa}

Kata tanya napa 'apa' dalam kalimat interogatifBK berfungsi menanyakan benda, tumbuh-tumbuhan, dan hewan.

Contoh:

Hia no pake waru napa?

'Dia memakai baju apa?'

Napa to tunamu?

'Apa yang kamu tanam?'
Tuaka ranca nopupu napa?

'Kakak sedang memetik apa?'

Tawonapa pobunguna?

'Daun apa pembungkusnya?'

Bau napa to i una ina?

'Ikan apa yang dimasak ibu?'

Tonci napa etu?

'Burung apa itu?'

\section{2) Kata Tanya Hema}

Kata tanya hema 'siapa' dalam kalimat interogatif BK berfungsi untuk menanyakan orang. Contoh:

Hema to nengkaho pu kaloku etu?

'Siapa yang memanjat pohon kelapa itu?'

Kuru ema ei?

'Kucing siapa ini?'

Tuai nopea hema?

'Adik menunggu siapa?'

Hema to mopodauka ko?

'Siapa yang akan menjahitnya?'

Yuli hema?

'Kata siapa?'

\section{3) Kata Tanya Nangkua}

Kata tanya nangkua 'mengapa' dalam kalimat interogatif BK berfungsi untuk menanyakan perbuatan, tujuan, dan alasan (sebab).

Contoh:

Ranca nongkua komi ei

'Sedang mengapa kamu ini?'

Nangkuako pade moma ko nehua nohikola?

'Mengapa kamu tidak masuk sekolah?' 
Nongkua hia nowebu anana?

'Mengapa dia memukul anaknya?'

Nongkua ina moma narata?

'Mengapa ibu tidak datang?'

Nongkua mama via/ i lida?

'Mengapa ayah di sawah?'

Napa pade nalino motoko?

'Mengapa diam saja?'

Napa pade moma ko nancili?

'Mengapa tidak pulang?'

Napa pade napane gaga?

'Mengapa panas sekali?'

Napa pade tumpu/Ina nowunta matana?

'Mengapa nenek menutup matanya?'

Napa pade nahodo hi aku dakoe?

'Mengapa kamu memarahi saya?'

\section{4) Kata Tanya Bewa}

Kata tanya bewa 'bagaimana' dalam kalimat interogatifBK berfungsiuntuk menanyakan keadaan, bentuk (rupa), dan cara.

Contoh:

Bewa bangkehena?

'Bagaimana keadaan istrinya?'

Bewa pohikolamu?

'Bagaimana sekolah kamu?'

Bewa akala mopua kau/ pu keu etu?

'Bagaimana cara memotong pohon cemara itu?'

Pahilokaa aku akalana?

'Tunjukkan padaku bagaimana caranya?'
Tari to bewa to i pokona tuai?

'Model bagaimana yang adik suka?'

\section{5) Kata Tanya Uma}

Kata tanya uma 'mana' dalam kalimat interogatif BK berfungsi untuk menanyakan tempat (arah) dan menanyakan sesuatu atau sesorang dari suatu kelompok. Kata tanya uma dapadat didahului dengan kata depan di, ke,dari, dan yang.

Contoh:

Uama doi to i tipakamua?

'Mana uang yang kamu janjikan?'

To koni ei lako rima?

'Makanan ini dari mana?'

Iko madota hau rima?

'Kamu mau ke mana?'

Tauna to uma etu he?

'Orang yang mana itu tadi?'

Watu to uma to raongko?,

'Batu yang mana akan diangkat?

\section{6) Kata Tanya Boloma}

Kata tanya boloma 'kapan' dalam kalimat interogatif BK berfungsi untuk menanyakan waktu.

Contoh:

Boloma tuaka mancili?

'Kapan kakak pulang?'

Lako boloma hia nancili lako Kulawi?

'Sejak kapan dia pulang dari Kulawi?'

Boloma rapamula motarena?

'Kapan dimulai latihannya?'

Du boloma ta mo pea?

'Sampai kapan kita menunggu?' 
Boloma ta mo pamula meguru?

'Kapan kita mulai belajar?'

\section{7) Kata Tanya Hangkua}

Kata tanya hangkua 'berapa' dalam kalimat interogatif BK berfungsi untuk menanyakan jumlah dan bilangan.

Contoh:

Hangku olina?

'Berapa harganya?'

Hangkua duami anamu?

'Sudah berapa anakmu?'

Toluna hangkua ongu

'Telurnya berapa butir?'

Hangkua dua anana?/hangkua kadea nana?

'Berapa banyak anaknya?'

Hangkua kuawa pomakea ta?

'Berapa jauh perjalanan kita?'

\section{8) Kalimat yang Ditandai dengan Kata Tanya}

Kalimat interogatifBK yang tidak menggunakan kata tanya ditandai dengan tanda tanya (?).

Contoh:

Ina to nodaukai?

'Ibu yang menjahitnya?'

Najadi di hau?

'Jadi dia pergi?'

Ngana-ngana etu noturu ra mo?

'Anak-anak itu sudah tidur?'

Iko nangkoni moko?

'Kamu sudah makan?'

Pamu nadua

'Kakimu sakit?'

\section{Simpulan}

Berdasarkan pembahasan dalam tulisan ini dapat disimpulkan beberapa hal sebagai berikut. Pertama, terdapat tiga bentuk kalimat interogatif yang ditemukan dalam BK, yaitu (1) bentuk kalimat introgatifYa-Tidak, (2) bentuk kalimat interogatif informasi, dan (3) bentuk kalimat interogatifretorik. Kedua, terdapat tujuh jenis kata tanya yang digunakan dalam BK yang masing-masing mempunyai fungsi tersendiri, yaitu (1) napa 'apa' berfungsi menayakan benda, tumbu-tumbuhan, dan hewan,(2) hema 'siapa', berfungsi untuk menanyakan orang, (3) nongkua 'mengapa' berfungsi untuk menanyakan perbuatan, tujuan, dan alasan (sebab),(4) bewa 'bagaimana', berfungsi untuk menanyakan keadaan, bentuk (rupa), dan cara,(5) uma 'mana', berfungsi untuk menanyakan tempat (arah) dan menanyakan sesuatu atau sesorang dari suatu kelompok,(6) boloma 'kapan', berfugsi untuk menanyakan waktu,(7) hangkua 'berapa' berfungsi untuk menanyakan jumlah dan bilangan.

\section{Daftar Pustaka}

Alwi, Hasan.Et al. 2003. Tata Bahasa Baku Bahasa Indonesia. Jakarta Balai Pustaka.

Chaer, Abdul. 2003. Linguistik Umum. Jakarta Rineka Cipta.

. 2006. Tata Bahasa Praktis bahasa Indonesia. Ediisi Revisi. Jakarta: PT Rineka Cipta.

Depertemen Pendidikan dan Kebudayaan. 1993. Kamus Besar Bahasa Indonesia. Jakarta: Depdikbud.

Dola, Abdullah. 2010. Tataran Sintaksis dalam Gramatika Bahasa Indonesia. Makassar: Badan Penerbit UNM.

Falah, M.Zaenal. 1988. Tata Bahasa Indonesia untuk SMTP-SMTA-Perguruan Tinggi. Yogyakarta: CV Karyono.

Kridalaksana, Harimurti. 2001. Kamus Linguistik.Edisi Ketia. Jakarta: PT Gramedia Pustaka Utama. 
Kusharyanti. Et al. 2005. Pesona Bahasa Langkah Awal Memahami Linguistik. Jakarta: PT Gramedia Pustaka Utama.

Ramlan, M. 1983.Morfologi Suatu Tinjauan Deskriptif. Yogyakarta: CV Karyono. Karyono.

Subroto, Edi. 1992. Pengantar Metoda Penelitian Linguistik Struktural. Surakarta: Sebelas Maret University Press.
Sudaryanto. 1993. Metode dan Aneka Teknik Analisis Bahasa. Yogyakarta: M. L. I. Komisariat Universitas Gajah Mada.

Verhaar, J.W.M. 1996. Asas-Asas Linguistik Umum. Yogyakarta: Gadjah Mada University Press. 